\title{
Selection and Manufacturing of Membrane Materials for Solar Sails
}

\author{
Robert G. Bryant ${ }^{1}$ \\ NASA Langley Research Center, MS 226, Hampton, VA 23681, USA \\ Shane T. Seaman ${ }^{2}$ \\ National Institute of Aerospace, 100 Exploration Way, Hampton, VA 23666, USA \\ W. Keats Wilkie ${ }^{3}$ \\ NASA Langley Research Center, MS 230, Hampton, VA 23681, USA \\ Masahiko Miyauchi ${ }^{4}$ \\ Kaneka Corp. 5-1-1, Torikai-Nishi, Settsu Osaka, 566-0072, Japan \\ Dennis C. Working ${ }^{5}$ \\ NASA Langley Research Center, MS 226, Hampton, VA 23681, USA
}

Commercial metallized polyimide or polyester films and hand-assembly techniques are acceptable for small solar sail technology demonstrations, although scaling this approach to large sail areas is impractical. Opportunities now exist to use new polymeric materials specifically designed for solar sailing applications, and take advantage of integrated sail manufacturing to enable large-scale solar sail construction. This approach has, in part, been demonstrated on the JAXA IKAROS solar sail demonstrator, and NASA Langley Research Center is now developing capabilities to produce ultrathin membranes for solar sails by integrating resin synthesis with film forming and sail manufacturing processes. This paper will discuss the selection and development of polymer material systems for space, and these new processes for producing ultrathin high-performance solar sail membrane films.

\footnotetext{
${ }^{1}$ Head, Advanced Materials and Processing Branch, NASA Langley Research Center, MS 226, Hampton, VA 23681, USA

${ }^{2}$ Graduate Student, National Institute of Aerospace, 100 Exploration Way, Hampton, VA 23666, USA

${ }^{3}$ Head, Structural Dynamics Branch, NASA Langley Research Center, MS 230, Hampton, VA 23681, USA

${ }^{4}$ Research Scientist, Kaneka Corp. 5-1-1, Torikai-Nishi, Settsu Osaka, 566-0072, Japan

${ }^{5}$ Research Materials Engineer, Advanced Materials and Processing Branch, NASA Langley Research

Center, MS 226, Hampton, VA 23681, USA
} 


\section{Introduction:}

The first use of polymer film as the primary structure for space technology was NASA's ECHO I. Launched in 1960, ECHO I was the first passive "reflector" communications satellite used to bounce microwave transmissions beyond the horizon.[1] ECHO I was an inflatable balloon constructed of 0.5 mil thick Mylar ${ }^{\circledR}$ film, both sides metalized with aluminum. The success of the series of these balloon-type structures, ECHO I, ECHO II and Explorer IX demonstrated the utility of polymeric materials for space applications. Beyond their intended use of scientific study, these satellites showed that sunlight solar pressure acts as the largest deforming force on these structures in the zero-gravity ultra-vacuum of space.[1] Additionally, this early work outlined 3 major areas of concern for the use of polymeric materials in long duration space missions. They were thermal $\left(-105\right.$ to $\left.150^{\circ} \mathrm{C}\right)$, photochemical effects resulting from ultraviolet (UV) radiation imparting $\left(\sim 0.75 \mathrm{~J} / \mathrm{cm}^{2}\right.$-min), and ionizing radiation (IR) (10-100 R/hr).[2] These effects can be additive and cause additional problems such as material loss, changes in physical properties, and accelerated degradation. These effects can be reduced if the dielectric films are protected with reflective and thermally conductive coatings, specific chemical structures, physical reinforcement, and electrostatic dissipaters. As the areal density of the laminated polymeric structure decreases, larger space structures can be developed per payload weight. Unfortunately the thinner the structural membrane, the more likely the space environmental effects will have on decreasing the lifetime of the space vehicle. The thermal effects, resulting from the $\mathrm{a}_{\mathrm{s}} / \mathrm{e}$ (absorptance/emittance), can increase membrane temperatures that may result in permanent distortion of the structural material leading to decreased performance and failure. When thermal effects are combined with IR and UV, additional mechanical failure modes, such as material ablation (radical fragmentation and static discharge), chemical hardening (radical crosslinking), and physical failure (cracking and tearing) will occur. Several possible solutions for these material based problems were: using a less dense polymer allowing for a thicker film, punching holes in the polymer film to lighten it and reduce solar pressure effects, developing a thermal control coating that conducts the absorbed heat energy over the entire surface of the balloon, thereby physically increasing the radiative surface area, and physically reinforcing the film membrane with battens or fibers.

Solar sail membranes are similar in construction and concepts used in the inflatable membrane structures, ECHO and Explorer. Their mission enabling performance was based on mission longevity, size, and areal density of the membrane and support structure in the space environment.[3-5] The primary performance metrics for sail materials are deployable reflective area, areal density, and operational temperature range.[6] Solar sail membranes 
have been made from Polyimides, such as CP1 for Nanosail-D, ISAS-TPI, for IKAROS, and polyesters such as polyethylene terephthalate $\left(\right.$ Mylar $\left.^{\circledR}\right)$ for the L'Garde solar sail demonstrator.[5,6] Commercial film materials are generally capable of meeting the less demanding performance criteria for most solar sail technology demonstration missions; however film thickness is often greater than desired. For long duration missions, partially aromatic polymers such as Mylar $^{\circledR}$ are more prone to degradation by space environmental factors such as temperature fluctuations, (UV) and cosmic radiation. Many other polymeric materials have flown in space for non-solar-sail applications, including thin films for use as flexible electronic cabling, solar array components, and flexible fabrics. Some of these materials could potentially serve as alternative solar sail materials.[2,7-9]

The process of solar sail manufacturing usually begins with the procurement of commercial-off-the-shelf (COTS) rolls of metalized film as stock material, followed by several basic sail assembly steps:[7,8,10]

1. Layout and seaming or bonding the films together.

2. Preparing for a secondary support structure (mast, battens, etc.).

3. Integrating secondary support structure to the sail membrane (bonding, lacing, etc).

4. Packaging the assembled sail structure (rolling, folding, etc.).

For small technology demonstrations, this process, and the use of COTS membranes and film materials that can be hand-assembled into a sail are suitable.[3,5] However, as the required sail area increases, Steps 1-4 become increasingly difficult. In particular, the addition of non-uniform, non-membrane structural features, e.g., bonded joints, stiffeners, rip-stops, etc., complicates the handling and packaging of large and delicate sail membranes, which may now no longer be easily roll processed.

For long-duration missions, and missions where large solar sail areas are required, an alternative approach is to begin with the processing of the film resin system itself. This affords several new possibilities for sail making:

- Creating ultrathin membranes on a continuous basis from most any resin system.

- Making films of nonuniform width, thickness, and mechanical orientation.

- Directly integrating rigid support structures, physical features, or functional material during film processing.

- Using "staged" reaction chemistry to tailor material process behavior.

- Metallizing films during a more advantageous point in the sail system production process. 
- More efficient direct packaging of the sail assembly, thereby decreasing manufacturing floor space requirements.

JAXA's Interplanetary Kite-craft Accelerated by Radiation Of the Sun (IKAROS) sail membrane used a new material, ISAS-TPI, jointly developed by JAXA and the Kaneka Corporation, using a nonstandard synthesis process. Rather than relying on the current methodology of selecting COTS materials and fitting them into a nonstandard application, the IKAROS team developed a material and process to fit the application. This is an important departure. Here, the polymer synthesis was designed to optimize material properties for that specific technology demonstration. [11] This provides others with an impetus to include other suitable polymers, and develop manufacturing processes that revolutionize how a large sail or blade is fabricated.

At NASA’s Langley Research Center (LaRC), high performance polymer development has been ongoing for over four decades. In fact, several LaRC polymeric systems have been commercially licensed. They include $\mathrm{CP} 1^{\mathrm{TM}}, \mathrm{CP} 2^{\mathrm{TM}}$, LaRC-SI ${ }^{\mathrm{TM}}$, and the PETI ${ }^{\mathrm{TM}}$ resin series. This paper will discuss the selection and development of polymer material systems for space, and a process that LaRC is developing to produce ultrathin high-performance membrane films.

\section{Discussion:}

The reason for using a polymeric membrane as the support structure for a solar sail is that in order to get the areal density required for mission performance, a metallic sail would be too physically frail to survive. Therefore, the most obvious solution is to find a material that is extremely thin, highly reflective and not effected by heat. However, until such a material is developed, coating one side of a durable lightweight material with a reflective material and the other side with a material that emits heat efficiently is the current best method. For use in Space, polymers suffer from three basic problems, they are dielectrics, thermal insulators, and lack broad-band reflectivity. However, they can be formed into most any shape and are inherently tough. In order to be enabling for Space applications, polymers are combined with other materials, coatings, fillers and fibers. The next process stage involves taking the polymer film and integrating structural support into the sail. The simplest process for reinforcing and building lengths of film into a planer rectangular sail or a sail blade have been studied in detail and referenced in the introduction. These studies are based using COTS metalized film as the starting point in the fabrication process. For rectangular sails, the process starts by cutting the metalized film, bonding structural support members, then taping or stitching the long edges of the film together to obtain the required sail dimension, and adding additional 
structural support to the sail as required using an adhesive. This method requires starting with metalized film, because the two-dimensional sail geometry would dictate the size and complexity of the thermal evaporator required to accurately deposit a layer of different metal on both sides of the polymer membrane. Additionally, as this membrane becomes thinner, additional infrastructure and care is required in handling the increased area of the sail. From a materials and manufacturing standpoint, the utility of this class of sail geometry is physically limited by the areal density, footprint, and deployment risk. The making of bladed sails were detailed in a similar fashion except that the film was cut to length, the film strips rotated 90 degrees, then sown together edge-to-edge to make the long blade. Reinforcements were added to the blade during assembly, as required.

There are many types of commercial polymeric materials to select as potential sail membranes (Table 1). The polymers are divided into three categories, aliphatic, partially aromatic and wholly aromatic. Aliphatic polymers, also referred to as polyolefins, are synthesized from unsaturated monomers and share the characteristic of single carbon-carbon (C-C) bonds along the polymer backbone. These bonds are highly susceptible to UV, IR, and radical attack (e.g. atomic oxygen). This results in the formation of radical and ionic organic fragments that recombine, attack, and propagate throughout the polymer, generating crosslinks and volatile organic fragments. These species have the effect of changing the physical properties of the film and accelerating the degradation of the material. Furthermore, aliphatic materials tend to lack the thermal stability and mechanical integrity associated with the other two groups of polymers. The partially aromatic polymers have double bonds and double bond character and have the classical resonance structure seen in the "circle-hexagon" unit, known as a benzene ring. These polymers gain an advantage from the resonance ring because the carbon atoms share a double bond $(\mathrm{C}=\mathrm{C})$, the ring structure is able to store electric charges generated by radical fragmentation and imparts a molecular stiffness that manifests itself through an increase in Tg and modulus. If a bond near or on the aromatic ring is broken, the atoms remain in place, increasing the chances for recombination of the severed atoms than radical propagation or volatile fragmentation. Thus, the addition of aromatic units within a polymer increases its thermal and radiation stability. Therefore, for the highest performance, a wholly aromatic polymer is a more logical choice.[11] These polymers tend to be higher in modulus, may not exhibit any melt flow or creep, and have strong intermolecular dipole interactions. These polymers possess the classic benzene ring structure throughout, and also have other ring structures (e.g. 5 membered imide ring) as part of the polymeric backbone. One thing to note is that in some of these polyimides, there is a C-C bond and a ring-O-ring single bond (Aryl ether). In discussing the C-C bond, the 
connecting atoms are either benzene rings or $-\mathrm{CF}_{3}$ carbons. These molecular structures impart the ability to stabilize radical charges and, in the case of oxygen, impart a partial resonance to the single oxygen atom via the unshared pairs of electrons orbiting the oxygen atom. Thus, the single bonds are reinforced single bonds imparting additional stability to the polymer. These aromatic polymers are characteristically radiation and UV resistant. However, like the majority of organic materials, they are susceptible to atomic oxygen attack, without the use of specific monomers designed to mitigate those effects. Although some of the polymers listed on Table 1, have found utility in Space, they are not available in the form factor required for a truly high performance solar sail. The reason is that the processes to make these material formats are optimized for other applications. Thus, using these materials as purchased may place limitations on some nontraditional applications, like solar sails.[11]

Polymer films are made by several standard processes; they include extrusion through a film die followed by roll-pressing, solution casing on a heated drum or belt and melt-blow forming (Figure 1). The melt-blow forming of polymer films is used for polymers that undergo melt flow, such as polyolefins and polyesters.

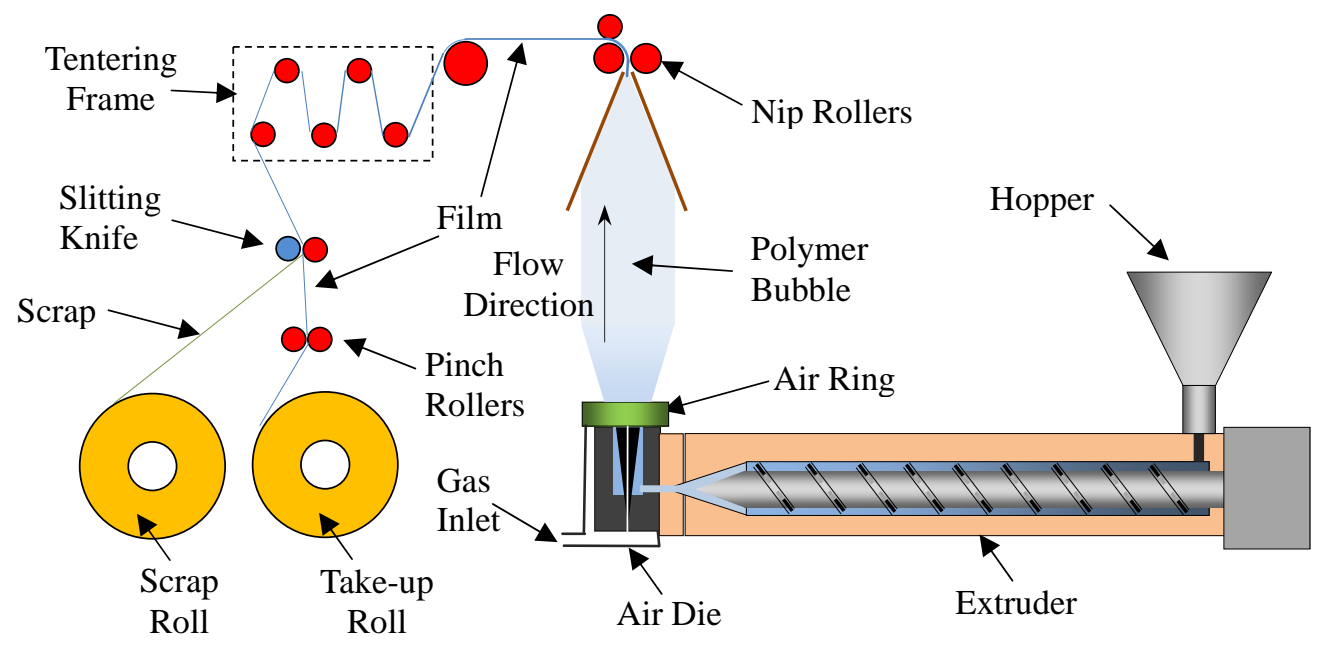

Fig. 1 Generalized Polymer Melt Blow-forming Film Process.

Here, polymer pellets are introduced into the hopper that feeds the extruder. The extruder melts and pressurizes the polymer and forces it through the air die which balances the air pressure inside the bubble controlling its size. The air ring keeps the molten film from touching, and adhering to, any external part of the die. As the bubble travels upward, it expands, becomes biaxially oriented and cools. As the polymer cools, its modulus increases and it is able to maintain its circumference. The film is then directed towards the Nip rollers where it is pinched together and fed down line into a tentering frame (optional) that further stretch orients and finishes the film. The film is then slit to 
size and taken up on a roller for additional post processing as required. Thus, the Nip rollers provide a film that has a minimal film width of the bubble circumference divided by 2, with a thickness nearly double that of the bubble wall. The advantage in a blow forming process is that the polymer film is biaxially oriented from the circumferential expansion of the bubble and the axial orientation from the upward pull of the Nip rollers, and a high quality surface is produced. The solution or gel film casting process uses a drum or belt, and a gel applicator in place of an extruder and air die system. This setup is required for films that cannot be easily melt processed, or the economics do not justify such a system. In a film casting process, the extrusion system is replaced with a heated drum or belt and the film is essentially dried and cured, prior to entering a tentering frame. However, when making ultrathin films, less than 1 micron, from polymers that are not readily melt processable, the gel casting method becomes increasingly difficulty as the film is dried, chemically staged and mechanically manipulated. The casting surface must be wider than the film, increasing the requirement of even heating, and highly polished without surface contaminates that could overwhelm the physical integrity of the sub-micron film. Since the film is so thin, it is possible to create pinholes, tears and cracks as the film shrinks and is stripped from the casting surface. Thus, a system similar to the melt blow forming technique could be employed (Figure 2).

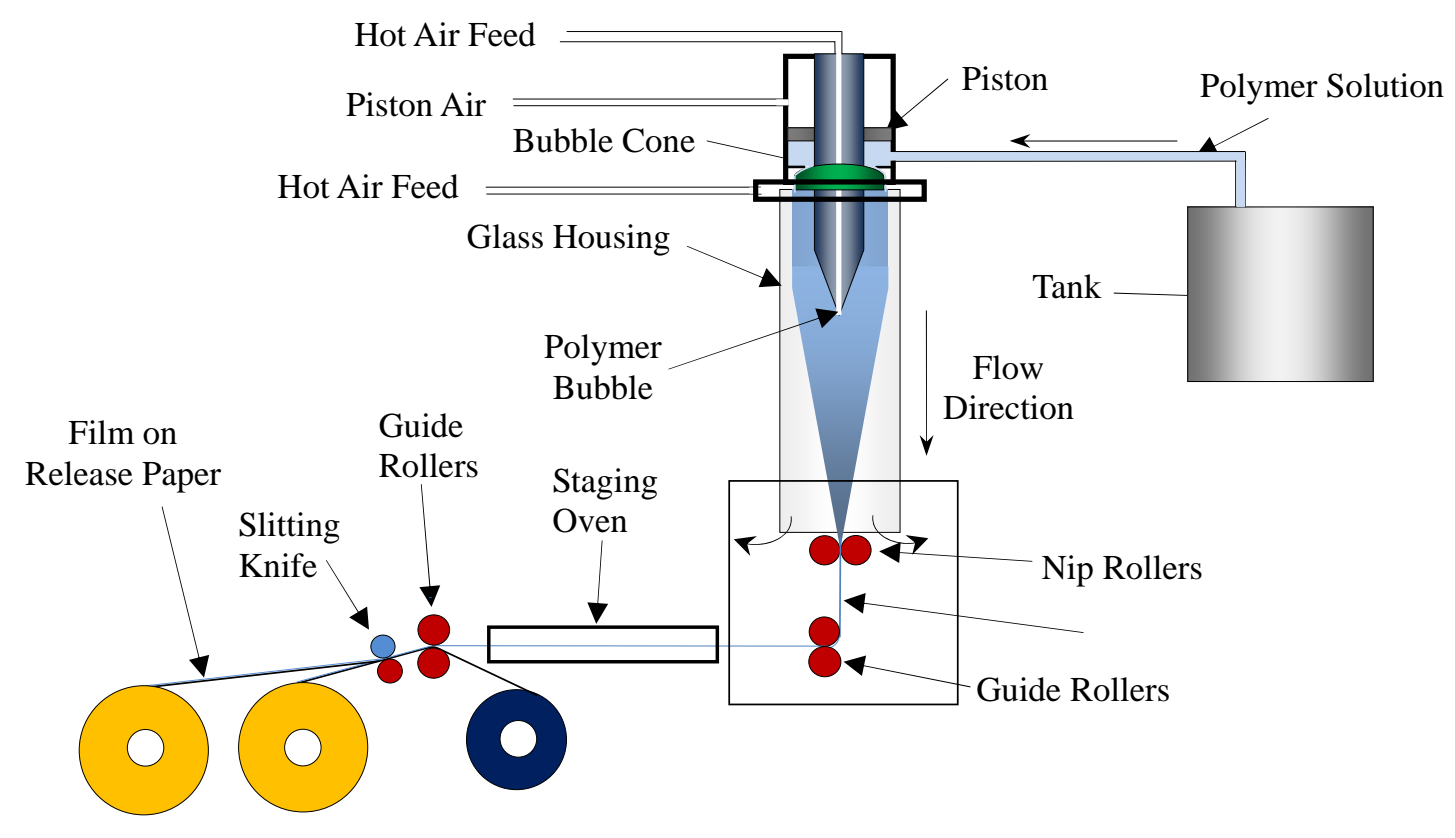

Fig. 2 Generalized Polymer Solution Blow-forming Film Process. 
Table 1 Polymers Used or Considered for Use in Space as Metalized Thin Films [12].

\begin{tabular}{|c|c|c|c|c|c|c|c|}
\hline & Unit Chemical Structure \& Name & $\begin{array}{c}\mathrm{Tg} / \mathrm{Tm} \\
\left({ }^{\circ} \mathrm{C}\right)\end{array}$ & $\begin{array}{c}\mathrm{CTE} \\
(\mathrm{ppm} / \mathrm{K}) \\
\end{array}$ & $\begin{array}{l}\text { Density } \\
\left(\mathrm{g} / \mathrm{cm}^{3}\right)\end{array}$ & $\begin{array}{c}\text { Tensile } \\
\text { Strength (kPA) } \\
\end{array}$ & $\begin{array}{c}\text { Thickness } \\
(\mu \mathrm{m})\end{array}$ & *Comment \\
\hline \multirow{2}{*}{ : } & $\begin{array}{c}-\mathrm{CCH}_{2} \mathrm{CH}_{2} \mathrm{f} \\
\text { Polyethylene (PE) }\end{array}$ & $\begin{array}{l}\sim-100 / \\
110-138\end{array}$ & $180-200$ & $0.9-1$ & 5 & 12 & $\begin{array}{l}\text { Not UV stable, melt processed, } \\
\text { can creep, poor adhesion. }\end{array}$ \\
\hline & $\begin{array}{c}\qquad \mathrm{fCF}_{2} \mathrm{CF}_{2} \mathrm{f} \\
\text { Polytetrafluoroethylene (PTFE or Teflon }{ }^{\circledR} \text { ) }\end{array}$ & $125 / 327$ & 135 & 2.15 & 21 & 25 & $\begin{array}{l}\text { An engineering polymer, not UV } \\
\text { stable in high Vacuum, can } \\
\text { creep, good hot-melt adhesive. }\end{array}$ \\
\hline \multirow{3}{*}{ 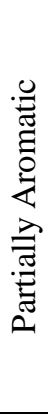 } & $\begin{array}{c}f_{\mathrm{C}}^{\mathrm{O}}-\mathrm{O}-\mathrm{COCH}_{2} \mathrm{CH}_{2} \mathrm{O} f \\
\text { Polyethylene Terephthalate "PET" }\left(\text { Mylar }^{\circledR}\right)\end{array}$ & $80 / 246$ & $60-65$ & 1.39 & 34 & 7 & $\begin{array}{l}\text { An engineering polymer, not UV } \\
\text { stable, melt processed resin. } \\
\text { Mainly used as a molding resin. }\end{array}$ \\
\hline & Polyethylene Naphthalate "PEN" (Teonex $\left.{ }^{\circledR}\right)$ & $120 / 270$ & $60-65$ & 1.36 & 34 & 7 & $\begin{array}{l}\text { An engineering polymer, not UV } \\
\text { stable, melt processed resin. } \\
\text { Slightly higher Tg than PET }\end{array}$ \\
\hline & $\begin{array}{c}\text { Polycarbonate }\left(\text { Lexan }^{\circledR}, \text { Macrofoil }^{\circledR}\right) \\
\text { Pochof }\end{array}$ & 145 & $75-80$ & 1.2 & 60 & 75 & $\begin{array}{l}\text { An engineering polymer, formed } \\
\text { through melt processing. A high } \\
\text { degree of toughness, UV Stable. }\end{array}$ \\
\hline \multirow{4}{*}{ 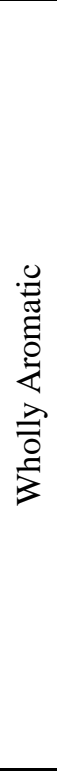 } & Polyimide $\left(\right.$ Kapton $^{\circledR}$, Apical $^{\circledR}$ ) & $360-410$ & $20-40$ & $\begin{array}{c}1.42- \\
1.54\end{array}$ & 33.5 & 7.5 & $\begin{array}{l}\text { A gel cast film. Considered } \\
\text { space durable, UV stable, creep } \\
\text { resistant, excellent thermal } \\
\text { stability, no melt flow, Tg is } \\
\text { theoretical. }\end{array}$ \\
\hline & Polyimide CP1 ${ }^{\circledR}$ & 263 & 50 & 1.43 & 14.5 & $2-3$ & $\begin{array}{l}\text { A gel cast film. Considered } \\
\text { space durable, UV stable, creep } \\
\text { resistant, excellent thermal } \\
\text { stability below Tg, heat sealable. }\end{array}$ \\
\hline & Polyimide CP2 ${ }^{\circledR}$ & 209 & 50 & 1.43 & 17 & $2-3$ & $\begin{array}{l}\text { A gel cast film. Considered } \\
\text { space durable, UV stable, creep } \\
\text { resistant, excellent thermal } \\
\text { stability below Tg, heat sealable. }\end{array}$ \\
\hline & $\begin{array}{c}\text { O } \\
\text { Polyimide ISAS-TPI (IKAROS) }\end{array}$ & 270 & Not Det. & Not Det. & Not Det. & 7.5 & $\begin{array}{l}\text { A gel cast film. Considered } \\
\text { space durable, UV stable, creep } \\
\text { resistant, excellent thermal } \\
\text { stability below Tg, soluble in the } \\
\text { Imide form, heat sealable.[11] }\end{array}$ \\
\hline
\end{tabular}

*Unless stated otherwise, physical properties are determined at $23^{\circ} \mathrm{C}$ and are approximate. 
In the diagram shown in Figure 2, the film is sent downward, rather than upward (Figure 1), because the polymer gel has a minimal amount of mechanical integrity and gravity will distort the bubble, scraping the material. The downward forming of the bubble has several unique dynamics, as the bubble size increases under flowing hot air; the solvent is driven off causing the polymer gel to contract. If the polymer is a reactive precursor, usually the case for many polyimides, there are curing mechanisms that also shrink the film, evolve volatiles, and cause a nonlinear change in viscosity, modulus and tensile strength. The formed film is very thin, biaxially oriented, and can be partially cured, supported and stored on release paper for additional post processing, (Figure 3). Bubble forming from solution requires additional process knowledge that involves downstream manipulation once the bubble is pressed into film at the Nip rollers. Some of the advantages of this process are that COTS resins and unique polymeric chemistries can be used that create high strength films that cannot melt-flow and are therefore thermally stable (degradation, physical properties and CTE) from cryogenic to above $300^{\circ} \mathrm{C}$. The intermediate chemical staging allows for post process heat sealing of these films that possess a Tg, or have residual solvent that helps with viscous flow prior to the final processing step. The film is not in physical contact until the Nip rollers which, due to their small diameter, are easier to surface finish than a large rotating belt or drum. These Nip rollers are easier to evenly heat and have minimal contact with the film. Lastly, a roll of film, blown from either process, can be used for other applications including, separation membranes, dielectric innerlayers, hot-melt bonding adhesives, and metalized for other products. Additional applications are available when certain filler particles are added to the resin prior to blow-forming (Figure 4). 


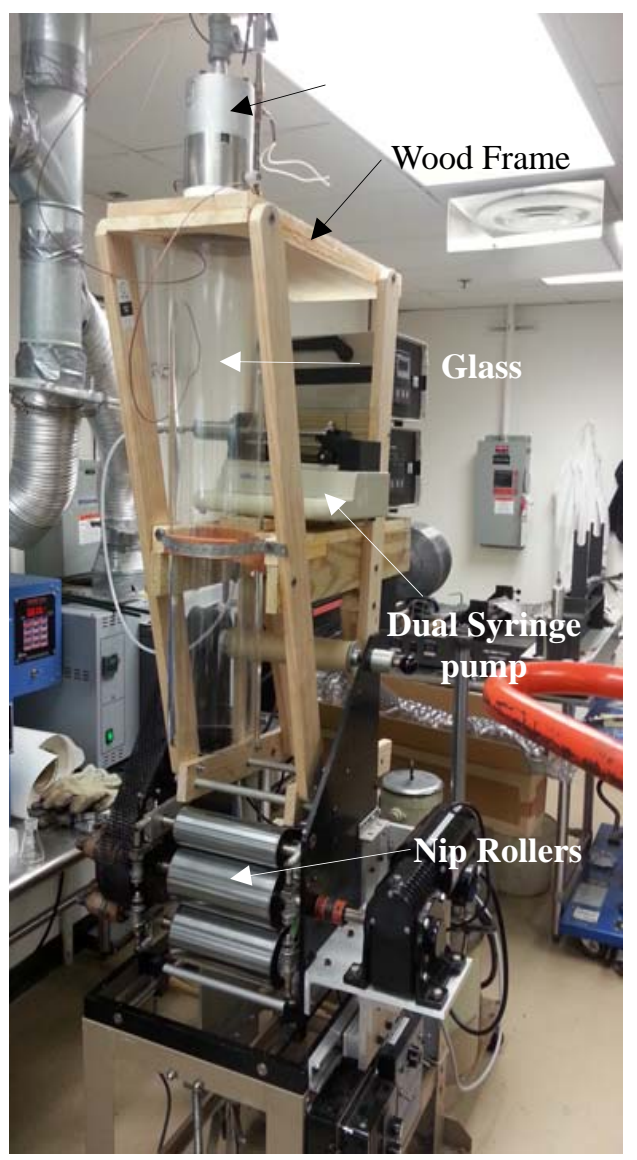

Fig. 3 NASA Langley's Prototype Polymer Solution Blow Film Caster.

At NASA's Langley Research Center, we have designed a lab scale prototype film caster that targets continuous production of $20 \mathrm{~cm}$ wide film (Figure 3). Pictured is the nearly complete assembly featuring the piston film forming head, glass enclosure, dual syringe pump, thermally control nip rollers and the take-up reel. The temporary wood stand allow for rapid adjustments in the configuration prior to optimization where aluminum framing elements will be used. This system will allow us to demonstrate the ability to produce ultrathin films from COTS resins, or our own chemistries. The advantage in exploring these different film chemistries is that properties can be tailored specifically for an application. For example, the polymers in metallized films rarely match the CTE of the metallic coatings over a broad temperature range. This is important if a mission requires that a solar sail need to approach the sun below 0.5 astronomical units (AU). Here, thermal build-up in the film can cause the metallic substrate to crack and peel, and the film can suffer permanent deformation or physical failure. There are two methods where this CTE matching can be achieved, by creating a metalized film that minimizes the temperature rise i.e. $\mathrm{a}_{\mathrm{s}} / \mathrm{e} \sim 0$, or using chemistry and fillers to tailor the CTE of the substrate to the metal coating. Below is a 
commercial product, developed and licensed from NASA, that uses a seamless polyimide belt with carbon nanotube (CNT) fillers. This Intermediate Transfer Belt (IBT) transfers the digital image from the 4 color dye Organic Photo Conductor (OPC) Drum onto the paper in color laser printers. This polymer film is made in-house by Kolon Industries of Korea specifically for this application that requires the right amount of electrical conductivity for image retention/renewal and thermal conductivity at elevated temperatures to avoid image distortion (Figure 4).
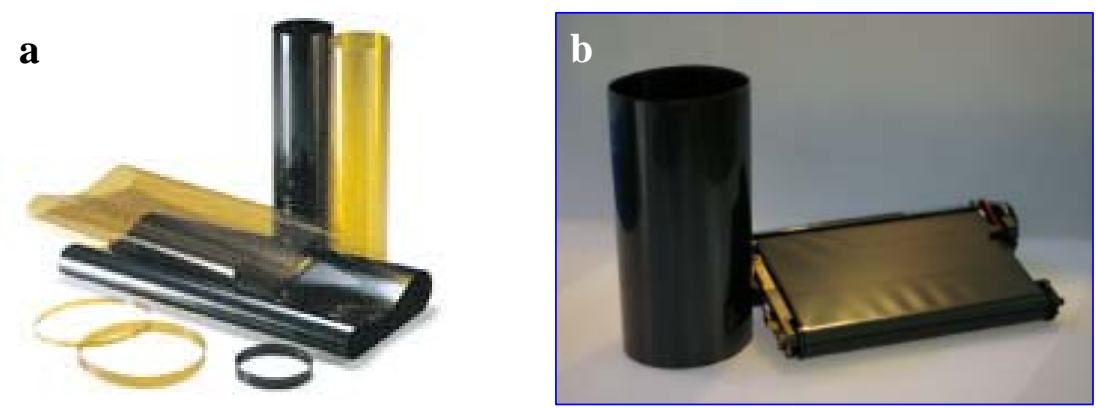

Fig. 4 (a) Filled (CNT) and neat resin polyimide belts, (b) IBT belt and IBT belt on mechanism.

A second approach would be to develop a film with the chemical structure that closely matches the CTE of the metallic coating, or using fillers that decrease the overall CTE of the polymer film towards that of the metal coating. Unlike rectangular sails, sail blades can be made by a different process starting with neat polymer film, including melt-blown or solution-blown film. Reinforcement is then added or processed into the membrane to increase rigidity prior to metallization. In order to do this, there should only be two different thicknesses, that of the film, and that of the reinforcing structure. This will assist in the degassing of the sail after folding or roll-up for pre-flight storage. The advantage of this method is that the process is scalable and therefore, sail area is theoretically unlimited.

The next process step involves taking the polymer film and integrating a structural reinforcement into the sail (Figure 5). Here the roll containing the thin polymeric film backed with release paper and fed through an embossing and cutting roller dies, that eject the scrap, and past a roll where the release paper is removed. Next, a roller die folds the film along the embossed lines and lightly heat bonds the layered film. The film is then passed through rotating folding bars that fold the film transversely while moving along with the film until the folds are clamped by heated blocks that hot press the film while the folding bars are rapidly removed, counter-rotated and moved back into position. The folded film then travels into a hot roller section where heated embossed rollers weld the folds of the film into a continuous reinforced edge with axial stiffeners and transverse battens, and remove any 
residual volatiles. The sail blade then passes through cold rollers, then punch rollers that put tiny holes in the sail to assist in degassing during roll-up, and to assist in making electrical connection during metallization.

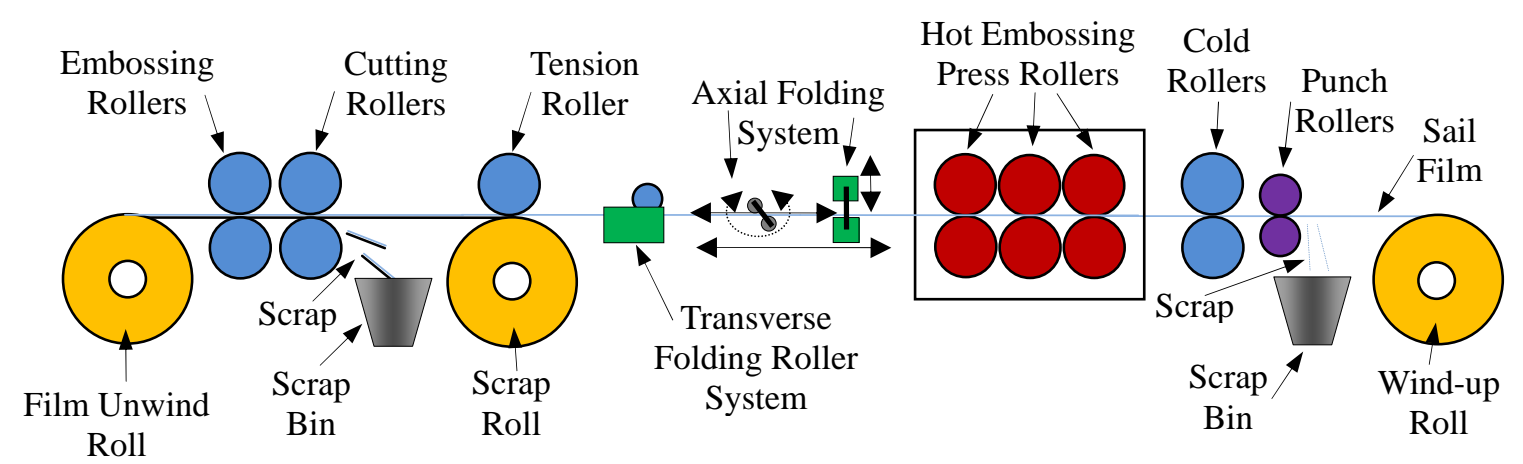

Fig. 5 Post Processing Line for Creating the Sail blade Architecture.

The details of folding the membrane to add different types of structural reinforcement on the sail blade are shown in Figures 6 and 7, and are some examples of 3 and 5 layer folded reinforcement. Table 2 contains the symbol key. Here, the punch out areas (6a and 7a) are required to fold the film, with biaxial reinforcement, into a continuous blade with only two thickness (6b,c and 7b,c). The reason for this is to avoid bumps and localized strains that occur on both roll-up and deployment. This allows the sail membrane to remain suspended between the thicker reinforced areas and to decrease static charge build-up during furling/unfurling. This also helps alleviate the effects of autoadhesion of the membrane material to itself during storage in an evacuated environment. For this reason, it is equally important that the fold spacing be equal depth on each side of the sail membrane.

Table 2 Key to Figures 6 and 7.

\begin{tabular}{|c|c|}
\hline Line Style & Key \\
\hline E- & 3 Layer Fold \\
\hline-------- & 2 Layer Fold \\
\hline$\ldots \ldots$ & Fold/Edge Line \\
\hline Bold Letters & Above Sail Film \\
\hline Gray Line & Underneath \\
\hline & Cut Out \\
\hline 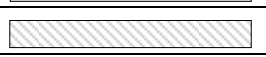 & 1 Layer Film \\
\hline DIIIIIIIII & 3 or 5 Layer Film \\
\hline
\end{tabular}


a

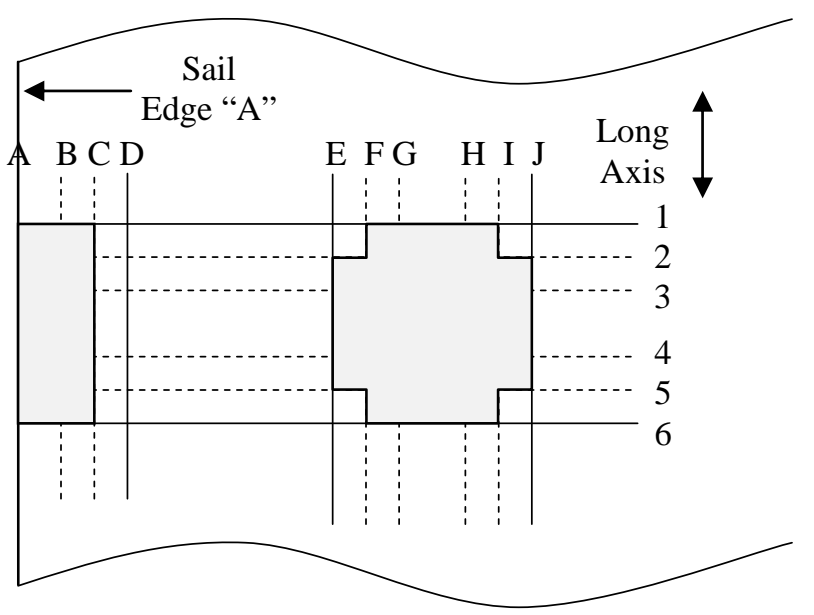

b

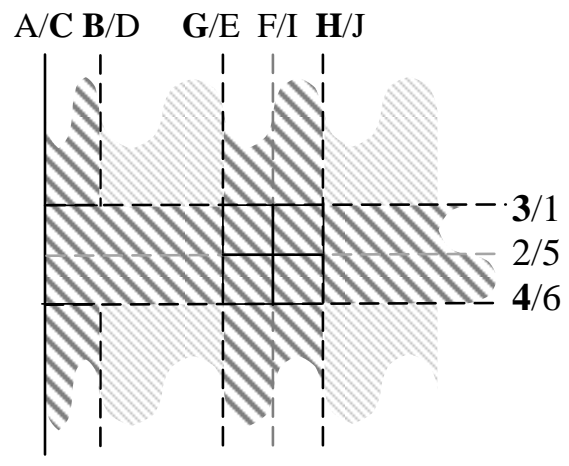

Fig. 6 3-Layer Folded Sail Membrane: (a) Film with Cutout Slots, (b) Folding Diagram, (c) Expanded Vertical View of folded sail without punch holes. 
a

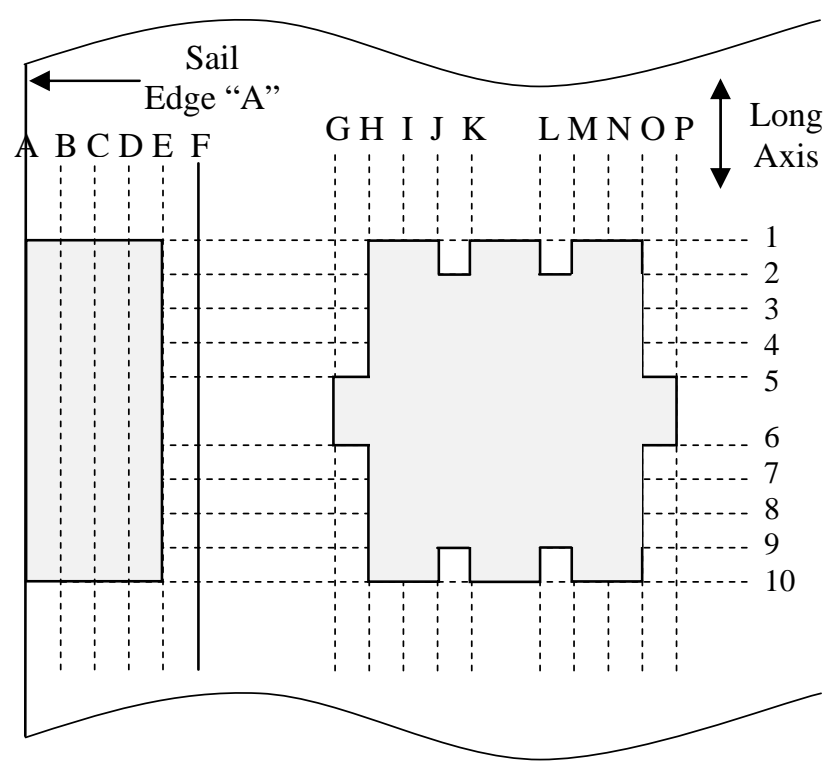

b

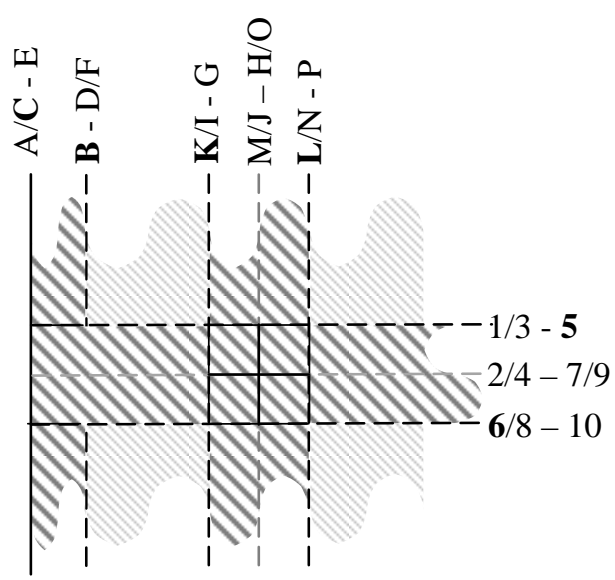

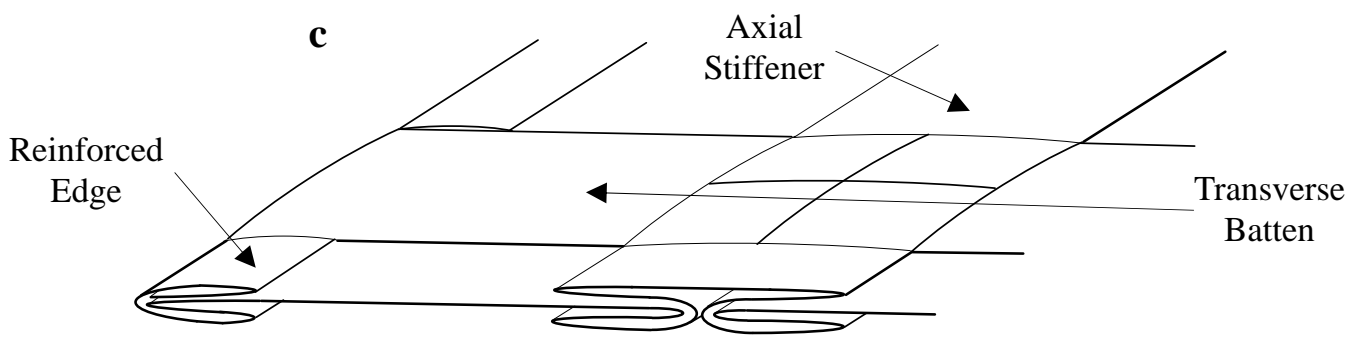

Fig. 7 5-Layer Folded Sail Membrane: (a) Film with Cutout Slots, (b) Folding Diagram, (c) Expanded Vertical View of folded sail without punch holes.

What is evident is that any internal support feature requires an odd number of folds, whereas the edge can take any thickness. The actual placement, number, width, thickness, and type(s) of the reinforcing folds comprising the structure depend on factors involving the sail parameters and the environmental requirements of the mission. These folds can be replaced by adhesive-backed tape or a hot-bonded structure, but then there are additional considerations of the effects that dissimilar materials may have on the sail over time.[11] This process requires additional fabrication hardware, especially if the film is extremely thin.

The last step involves metalizing the blade (Figure 8). Here, the folded membrane wind-up reel (Figure 5) becomes the sail membrane reel and the blade is fed into two metal deposition chambers that deposit a layer of metal on each side of the folded film. 


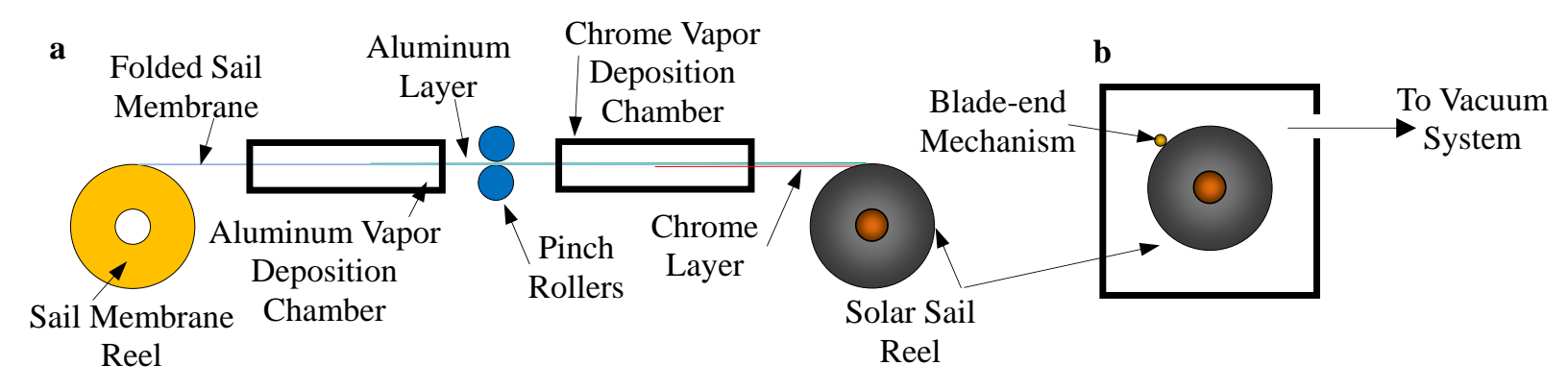

Fig. 8 (a) Continuous Two Sided Metallization of the Sail Blade Membrane, (b) Vacuum Degas and Storage.

As previously stated, the minute punched-out holes in the blade provide a conductive pathway connecting the metallic layers thereby alleviating static charge buildup across the dielectric membrane, and allows for degassing of trapped air during storage. The post-metalized sail blade is then wound onto the solar sail reel, slowly degassed and stowed until unfurling is required.

\section{Conclusions:}

In order for Solar Sails to be selected as mission enabling technology, the move away from COTS technology for the sail membrane, and traditional solar sail design may have to occur. This shift has already taken place with the IKAROS solar sail demonstrator. However, more progression is needed, especially in the sail material and construction. This paper has put forward construction methods, which are current manufacturing practices, which could be applied towards the advancement of the major enabling factor for solar sails, the sail material. Here, the advocacy is focused on optimizing materials and processes, rather than compromising the application with a COTS material. The details of basic chemistry, thin film manufacture, mitigating static charge build-up, building in several types of reinforcement, roll-to-roll evaporative coating, and post-storage degassing issues, have been covered to the point where subject matter experts can began to design in the further details.

\section{References:}

[1] George F. Pezdirtz, “Composite Materials in Erectable Space Structures - ECHO Satellites”, NASA TM-78340, Presented at the $18^{\text {th }}$ Annual Technical and Management Conference Sponsored by the Society of the Plastics Industry, (1963).

[2] Edwards, D, L., Hollerman, W. A., Hubbs, W. S., Gray, P. A., Wertz, G. E., Hoppe, D. T., Nehls, M. K., Semmel, C. L. “Electron Radiation Effects on Candidate Solar Sail Material”, NTIS Server CASI Doc. I.D. 20040000467 (2003).

[3] McInnes, C. R., Solar Sailing: Technology, Dynamics and Mission Applications, Springer Praxis, New York, 1999.

[4] W.M. Rowe, E.E. Luedke and D.K. Edwards, “Thermal Radiative Properties of Solar Sail Film Materials”, $2^{\text {nd }}$ AIAA/ASME Thermophysics and Heat Transfer Conf., Palo Alto, CA /May 24-26, 1978. 
[5] Rikio Yokota, Masahiko Miyauchi, Motoyasu Suzuki, Andoh Ayumi, Kazama Ken-ichi,Yuichi Ishida, Jun-ichiro Ishizawa, “Asymmetric Aromatic Polyimide Chemistry and New Generation, Heat Resistant Polyimides (ISAS-TPI) for IKAROS Membrane”, SAMPE Technical Conf Electronic Proceedings, Paper \#2443, Oct (2012).

[6] Les Johnson, Roy Young, Edward Montgomery, Dean Alhorn, “Status of solar sail technology within NASA”, Advances in Space Research, 48, pp 1687-1694, (2011).

[7] Hans U. Schuerch, "Materials and Fabrication Methods for Deployable Thin Film Structures Used in Space Operations”, ARC-R-374, submitted to the MacNeal-Schwendler Corporation under Subcontract 73-001, Prime Contract NAS7-699, February 19, 1970.

[8] T. F. Origer J. B. Daniels, D. M. Dowdle, D. W. Hahn, E. N. Hildreth, D.R. Lagerquist, E. J. Mahagnoul, and J. B. Munson, “Preliminary Solar Sail Design and Fabrication Assessment, *Spinning Sail Blade, *Square Sail Sheet”, NASA-CR-155591 FINAL REPORT, June 22, 1977.

[9] Michael Fuedman and Gerard Walsh, “High Performance Films: Review of New Materials and Trends”, Polym. Eng. \& Sci., 42(8), pp 1756-1788, (2002).

[10] "Preliminary Design and Fabrication Assessment for Two Solar Sail Candidates”, Prepared Under Contract No. 954720 for Jet Propulsion Laboratory, California Institute of Technology 4800 Oak Grove Drive Pasadena, California by ILC Dover, Box 266, Frenerica, DE 19946, July I, 1977.

[11] Masahiko Miyauchi, Kaneka Corp, Japan, Personal Communication, May, 2013.

[12] Data from Boedeker Plastics Materials Guide, http://www.boedeker.com/mguide.htm. [cited 1 May 2013]. 